\title{
Evidence for the involvement of the cyclooxygenase- metabolic pathway in diclofenac-induced inhibition of spontaneous contraction of rat portal vein smooth muscle cells
}

\author{
Keiichi Shimamura ${ }^{1}$, Shinichi Kimura ${ }^{1}$, Ming ZHOU ${ }^{2}$, Yue $\mathrm{WANG}^{2}$, \\ Miyuki TOBA ${ }^{1}$, Atsuko OHASHI ${ }^{1}$, Takashiro HIGUCHI ${ }^{3}$, \\ Hideaki KAWAGUCHI ${ }^{4}$ and Kenji KITAMURA ${ }^{5}$ \\ ${ }^{1}$ Department of Clinical Pharmacology, Faculty of Pharmaceutical Sciences, Health \\ Sciences University of Hokkaido, Ishikari-Tobetsu, Hokkaido 061-0293, Japan \\ ${ }^{2}$ Department of Pharmacology, Medical College of Qingdao University, The People's \\ Republic of China \\ ${ }^{3}$ Department of Integrated Human Sciences, Faculty of Pharmaceutical Sciences, Health \\ Sciences University of Hokkaido, Japan \\ ${ }^{4}$ Department of Laboratory Medicine, Hokkaido University Graduate School of \\ Medicine, Japan \\ ${ }^{5}$ Department of Physiological Science and Molecular Biology, Fukuoka Dental College, \\ Japan
}

\begin{abstract}
The effects of diclofenac, a cyclooxygenase (COX) inhibitor, were investigated on spontaneous phasic contractions of longitudinal preparations of the rat portal vein. Diclofenac produced a concentration-dependent decrease in the amplitude of these spontaneous phasic contractions. Diclofenac $(30 \mu \mathrm{M})$ decreased the amplitude of the spontaneous phasic increase in the $\mathrm{F}_{340} / \mathrm{F}_{380}$ ratio of Fura PE3, an indicator of intracellular $\mathrm{Ca}^{2+}$ concentration. It also reduced the number of action potentials in each burst discharge without changing the resting membrane potential of longitudinal smooth muscle cells. The extent of the distribution of Lucifer Yellow injected into a smooth muscle cell was decreased in the presence of diclofenac $(30 \mu \mathrm{M})$. Both AH6809, a prostanoid EP receptor antagonist, and SQ22536, an adenylate cyclase inhibitor, decreased the amplitude of the spontaneous contractions. On the other hand, neither ozagrel, a thromboxane synthase inhibitor, nor SQ29548, a prostanoid TP receptor antagonist, significantly affected spontaneous contractions. These results indicate that diclofenac inhibits the amplitude of spontaneous contractions of the rat portal vein through inhibition of electrical activity, which may be related to an inhibition of the cyclooxygenase pathway.
\end{abstract}

Key words: diclofenac, portal vein, contraction, intracellular $\mathrm{Ca}^{2+}$, membrane potential

Correspondence to: Keiichi Shimamura, Ph.D., Department of Clinical Pharmacology, Faculty of Pharmaceutical Sciences, Health Sciences University of Hokkaido, 1757 Kanazawa, Ishikari-Tobetsu, Hokkaido 061-0293, Japan

Phone: +81-133-23-3915 Fax: +81-133-23-1669 e-mail: shimamu@hoku-iryo-u.ac.jp 


\section{Introduction}

Longitudinal preparations of the rat portal vein develop spontaneous phasic myogenic contractions which are accompanied by bursts of action potentials (Funaki and Bohr, 1964; Axelsson et al., 1967; Johansson et al., 1967). Because such contractions are very sensitive to extracellular calcium, the rat portal vein has been used to examine the effects of drugs on vascular contraction (Sutter, 1990). Products of the cyclooxygenase (COX) pathway have been shown to be involved in the regulation of physiological activities (Wright et al., 2001). Spontaneous contractions of the rat portal vein have been shown to be potentiated by prostaglandin $\mathrm{E}_{1}\left(\mathrm{PGE}_{1}\right)$ (Miwa et al., 1997) and arachidonic acid (Vidulescu et al., 2000). On the other hand they are inhibited by meclofenamate, a COX inhibitor (Enero, 1979), although the mechanism involved in this inhibition has not been determined. In this study, we have examined the effect of diclofenac, another COX inhibitor (Mitchell et al., 1994), on spontaneous contractions of smooth muscle cells of the rat portal vein, as well as on their membrane potential and intracellular $\mathrm{Ca}^{2+}$ concentration. Products of the COX pathway act on prostanoid receptors, which use different intracellular mediators (Wright et al., 2001). To identify the product involved in this spontaneous contraction, we examined the effects of prostanoid receptor antagonists and an adenylate cyclase inhibitor on these spontaneous contractions. Cell-to-cell coupling has been shown to play an important role in propagation of excitation and therefore the coordination of vascular responses (Christ et al., 1996). Therefore, we have examined the effect of diclofenac on the distribution of Lucifer Yellow injected intracellularly, as this has been used to evaluate intercellular communication (Beny, 1990). The results obtained indicate that COX may play a role in the generation of spontaneous contractions in the rat portal vein.

\section{Materials and Methods}

Male Wistar rats weighing 200-300 g were anesthetized using $\mathrm{CO}_{2}$, and treated according to the Guiding Principles for the Care and Use of Laboratory Animals Approved by the Japanese Pharmacological Society. The hepatic portal vein was isolated and preparations of the longitudinal smooth muscle layer dissected under a binocular microscope and placed in a modified Tyrode's solution. The luminal surface of the tissue was rubbed with paper to remove the endothelium. The composition of the modified Tyrode's solution (in $\mathrm{mM}$ ) was as follows: $137 \mathrm{NaCl}, 5.4 \mathrm{KCl}, 2.0 \mathrm{CaCl}_{2}, 1.0 \mathrm{MgCl}_{2}, 0.4 \mathrm{NaH}_{2} \mathrm{PO}_{4}, 11.9 \mathrm{NaHCO}_{3}, 5.6$ glucose, with a pH of 7.3. The high $\mathrm{K}^{+}$-Tyrode's solution was made by replacing $\mathrm{NaCl}$ with an equimolar concentration of $\mathrm{KCl}$. All experiments were conducted at $37^{\circ} \mathrm{C}$ in Tyrode's solution aerated continuously with a mixture of $95 \% \mathrm{O}_{2}-5 \% \mathrm{CO}_{2}$. In the contractile force recording experiments, each preparation was mounted vertically in an organ bath. The isometric contractile force of preparations was measured using a force-displacement transducer (U-gage 10G, Minebea, Karuizawa, Japan) equipped with a strain amplifier (AS2102, NEC, Tokyo, Japan) and recorded with a thermal-pen recorder (Linearcorder WR3310, Graphtec, Tokyo, Japan).

Changes in intracellular $\mathrm{Ca}^{2+}$ concentrations were estimated according to our previous report (Shimamura et al., 2003). The surfaces of all materials used for the $\mathrm{Ca}^{2+}$-indicator- 
experiment were coated with silicon using Siliconizer L-25 (Fuji System, Tokyo, Japan). The small adventitia and endothelium-removed longitudinal strips of rat portal vein were incubated with Fura-PE3/AM (Wako, Osaka, Japan) $20 \mu \mathrm{M}$ dissolved in dimethyl sulfoxide (DMSO) and $0.08 \%$ Pluronic F-127 in Tyrode's solution for 2 hours at room temperature. The preparations were then mounted adventitial-side down on a silicon rubber in the temperature-controlled chamber of a fluorometer (CAF 100, JASCO, Tokyo, Japan). Intracellular $\mathrm{Ca}^{2+}$ concentrations were estimated from the luminescence intensity ratio $\left(\mathrm{F}_{340} / \mathrm{F}_{380}\right)$ when excited at wavelengths of $340 \mathrm{~nm}\left(\mathrm{~F}_{340}\right)$ and $380 \mathrm{~nm}\left(\mathrm{~F}_{380}\right)$. One end of each preparation was connected to a forcedisplacement transducer so that changes in tension could be measured simultaneously. Isometric tension and fluorescence were recorded on a pen recorder (Yokogawa LR4220, Tokyo, Japan) and stored in a PCM recorder (RD101-T, TEAC, Tokyo, Japan). Mirror images in both $\mathrm{F}_{340}$ and $\mathrm{F}_{380}$ were considered to be a marker of the successful measurement of $\mathrm{F}_{340} / \mathrm{F}_{380}$ without movement interference. After each experiment, preparations were first exposed to $40 \mathrm{mM} \mathrm{K}{ }^{+}$ Tyrode's solution and then subsequently exposed to 2 mM EGTA in a $\mathrm{Ca}^{2+}$-free Tyrode's solution to determine the minimum level of intracellular $\mathrm{Ca}^{2+}$. Changes in the fluorescence ratio were expressed as a percentage of the elevation induced by the $40 \mathrm{mM} \mathrm{K} \mathrm{K}^{+}$Tyrode's solution. The contraction induced by the $40 \mathrm{mM} \mathrm{\textrm {K } ^ { + }}$ Tyrode's solution had a stable amplitude which was slightly, but not significantly, less than that induced by the $50 \mathrm{mM} \mathrm{K}^{+}$Tyrode's solution.

The membrane potential was measured by the microelectrode technique as reported previously (Shimamura et al., 2003). Adventitia and endothelium-removed longitudinal strips were mounted adventitial-side up on a silicon rubber bed in a chamber that was continuously perfused with warmed Tyrode's solution at a flow rate of $5 \mathrm{ml} / \mathrm{min}$. A pulled glass capillary microelectrode (PN-3, Narishige, Tokyo, Japan), filled with $3 \mathrm{M} \mathrm{KCl}$ and with a tip resistance of $40 \mathrm{M} \Omega$, was impaled from the adventitial side. Membrane potentials were monitored using a microelectrode amplifier (Intra 767 Electrometer, World Precision Instruments, Sarasota, FL, USA) and recorded through both a thermal pen recorder (Graphtec Lineacorder WR3310) as well as a PCM recorder (RA125T, TEAC, Tokyo, Japan). Data were retrieved using both Axotape (Axon Instruments, Fostercity, USA) and Labmaster (Scientific Solutions, Inc., Mentor, OH, USA) software in an IBM-compatible PC.

Intercellular diffusion capability was estimated by detection of the fluorescent signals of neighboring cells following injection of Lucifer Yellow (Sigma Chemical Co. St. Louis, MO, USA) as reported by others (Beny and Connat, 1992; Sakai et al., 1992). A 4\% solution of Lucifer Yellow (Lucifer Yellow dissolved in $150 \mathrm{mM}$ Lithium chloride) was back-filled into the microelectrodes using a resistance of 200-300 M $\Omega$. The dye was considered to be successfully loaded when a stable membrane potential of below $-40 \mathrm{mV}$ was recorded with action potentials of more than $30 \mathrm{mV}$ in amplitude both before and after the Lucifer Yellow injection. During impalement of single longitudinal smooth muscle cells of the rat portal vein, dye was injected with a hyperpolarizing direct current $(0.35 \mathrm{nA})$ for 2 minutes. When dye injection was complete, preparations were suspended vertically in Tyrode's solution for 10 minutes and the tissue then fixed with $4 \%$ paraformaldehyde. In experiments with Lucifer Yellow, diclofenac $30 \mu \mathrm{M}$ was added to the perfusate 5 min prior to dye injection. To evaluate the extent of intercellular dye diffusion, preparations were examined with a fluorescence microscope (DMIRB/E, Leica 
Microsystem, Wetzlar, Germany). Preparations were excited at $480 \mathrm{~nm}$ and the resulting fluorescence recorded at $520 \mathrm{~nm}$ with a CCD camera (Hamamatsu, Japan) and the data stored on a computer hard disk.

\section{Drugs}

Diclofenac sodium, prostaglandin $\mathrm{E}_{2}\left(\mathrm{PGE}_{2}\right)$ and $1 \mathrm{H}-[1,2,4]$ oxadiazolo [4,3-a] guinoxalin-1one (ODQ) were from Wako Pure Chemical (Osaka, Japan); 6-isopropoxy-9-oxoxanthene-2carboxylic acid (AH6809) and [1s-[1 $2,2 \alpha(Z), 3 \alpha, 4 \alpha]]-7-[3-[[2-[($ phenylamino) carbonyl] hydrazino] methyl]-7-oxabicyclo [2.2.1] hept-2-yl]-5-heptenoic acid (SQ29548) from Cayman Chemical (Ann Arbor, MI, USA); 9-(tetrahydro-2-furanyl)-9H-purin-6-amine (SQ22536) from Calbiochem (San Diego, CA, USA) and ozagrel $\mathrm{HCl}$ and DMSO were from Sigma Chemical Co. (St. Louis, MO, USA). AH6809 was dissolved in $37.7 \mathrm{mM} \mathrm{Na}_{2} \mathrm{CO}_{3}$ to make a $10 \mathrm{mM}$ stock solution. $\mathrm{PGE}_{2}$ was dissolved in ethanol to make $1 \mathrm{mM}$ stock solution. ODQ was dissolved in DMSO to make a $10 \mathrm{mM}$ stock solution. SQ29548 was dissolved in DMSO to make a $1 \mathrm{mM}$ stock solution. In experiments with the above drugs, the final concentration of DMSO and ethanol was less than $0.1 \%$ and $0.001 \%$, respectively. These concentrations of DMSO and ethanol did not affect the contraction of the rat portal vein.

\section{Data analysis}

Results are given as the mean \pm SEM with the number of preparations in parenthesis. Statistical significance was assessed using the Student $t$-test. Paired $t$-test's were used when appropriate. $P$ values $<0.05$ were considered to be statistically significant.

\section{Results}

\section{Effects of diclofenac on spontaneous contraction}

The rat portal vein exhibited spontaneous phasic contractions with a stable frequency of 4.1 $\pm 0.6 \mathrm{cpm}(\mathrm{n}=15)$. The amplitude of these spontaneous phasic contractions was stable at $1.4 \pm$ $0.1 \mathrm{mN}(\mathrm{n}=14)$ and was $41.6 \pm 2.7 \%(\mathrm{n}=9)$ of that developed in $50 \mathrm{mM} \mathrm{K} \mathrm{K}^{+}$-Tyrode's solution. Five to $10 \mathrm{~min}$ after administration, diclofenac $10 \mu \mathrm{M}$ lowered the amplitude of the spontaneous contractions of the rat portal vein by $59.4 \pm 2 \%(n=10)$ without a marked change in the contraction frequency. The inhibition of the contractile amplitude by diclofenac was concentration-dependent (Fig. 1). The amplitude of contraction induced by $50 \mathrm{mM} \mathrm{K}^{+}$in the presence of $30 \mu \mathrm{M}$ diclofenac was $96.2 \pm 1.9 \%(\mathrm{n}=5)$ of that in the absence of diclofenac. When the amplitude of spontaneous contractions was decreased by $10 \mu \mathrm{M}$ diclofenac, administration of $10 \mathrm{nM} \mathrm{PGE}_{2}$ restored the amplitude to $94.1 \pm 4.9 \%(\mathrm{n}=7)$ of that before administration of diclofenac.

\section{Effects of diclofenac on intracellular $\mathrm{Ca}^{2+}$ concentration}

During the simultaneous recording of the Fura PE3 $\mathrm{F}_{340} / \mathrm{F}_{380}$ ratio and the force of contraction, we observed that spontaneous phasic contractions were generated synchronously with a phasic increase in the $\mathrm{F}_{340} / \mathrm{F}_{380}$ signal. The amplitude of these spontaneous contractions 

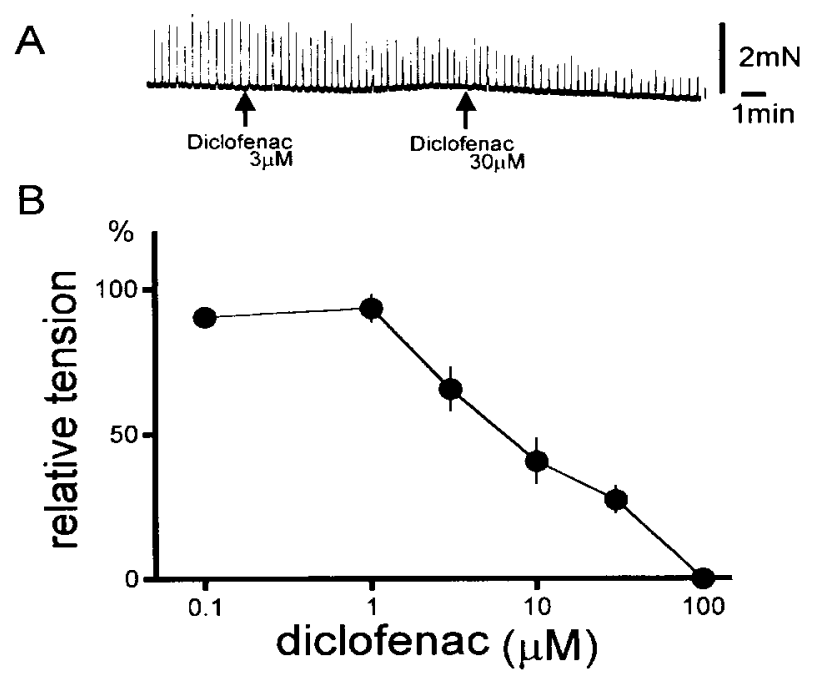

Fig. 1. Effect of diclofenac on spontaneous contractions of longitudinal preparations of the rat portal vein. A: A typical trace showing the inhibitory effects of $3 \mu \mathrm{M}$ and $30 \mu \mathrm{M}$ diclofenac on these contractions. B: A summary plot showing the concentrationdependent depression of the amplitude of the spontaneous contractions by diclofenac. An average of the consequent amplitudes of 5 to $10 \mathrm{~min}$ recordings of the contractions in the presence and absence of various concentrations of diclofenac was used as a representative value for each preparation. Each point shown in the figure represents the mean of data from 5 to 10 preparations.

was $39.6 \pm 8.7 \%(n=7)$ of that developed in $40 \mathrm{mM} \mathrm{K} \mathrm{K}^{+}$-Tyrode's solution. The amplitude of the

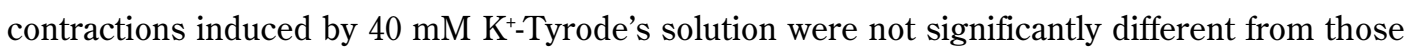
in $50 \mathrm{mM} \mathrm{K}$-Tyrode's solution. The maximum intensity of the $\mathrm{F}_{340} / \mathrm{F}_{380}$ signals was $37.0 \pm 3.0 \%$ $(\mathrm{n}=7)$ of that developed in $40 \mathrm{mM} \mathrm{K}$-Tyrode's solution. The increase of the ratio was inhibited by incubation of the nominally $\mathrm{Ca}^{2+}$-free Tyrode's solution. The amplitude of the Fura PE3 $\mathrm{F}_{340} /$ $\mathrm{F}_{380}$ ratio in the control was $40.2 \pm 10.0 \%(\mathrm{n}=5)$ and it was decreased by $30 \mu \mathrm{M}$ diclofenac to 8.8 $\pm 4.1 \%(\mathrm{n}=5)$ (Fig. 2).

\section{Effects of diclofenac on the membrane potential}

The spontaneous action potential bursts that appeared periodically in the rat portal vein preparations could be inhibited by reduction of the $\mathrm{Ca}^{2+}$ concentration in the Tyrode's solution or by application of $1 \mu \mathrm{M}$ nicardipine (data not shown). Diclofenac (30 $\mu \mathrm{M})$ did not change the resting membrane potential (control, $-43.6 \pm 1.3 \mathrm{mV}, \mathrm{n}=19 ; 30 \mu \mathrm{M}$ diclofenac, $-46.0 \pm 1.2 \mathrm{mV}$, $\mathrm{n}=20$ ). However, it markedly inhibited the number of action potentials in each burst (Fig. 3). The number of action potentials in each burst was $7.0 \pm 1.3(\mathrm{n}=11)$ in the absence of diclofenac and $2.0 \pm 0.6(\mathrm{n}=11)$ in the presence of $30 \mu \mathrm{M}$ diclofenac.

Effects of a thromboxane synthesis inhibitor and of prostanoid receptor antagonists on spontaneous contraction

Neither ozagrel, a thromboxane synthase inhibitor, nor SQ29548, a prostanoid TP receptor 

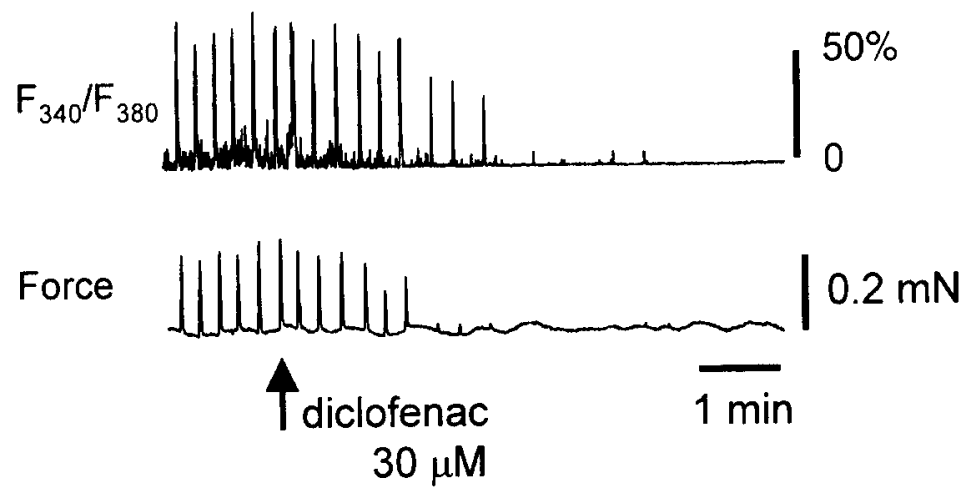

Fig. 2. Effect of $30 \mu \mathrm{M}$ diclofenac on the spontaneous intensity increases in the Fura-PE3 fluorescence ratio $\left(\mathrm{F}_{340} / \mathrm{F}_{380}\right)$ (upper trace) and contraction force (bottom trace). The fluorescence intensity ratio is expressed as a \% of the change induced by $40 \mathrm{mM} \mathrm{K} \mathrm{K}^{+}$ Tyrode's solution.

\section{control}

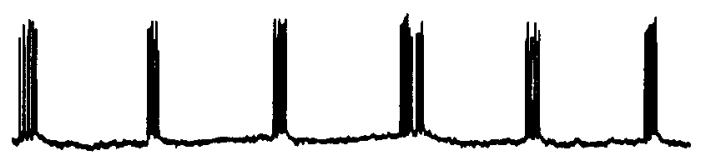

diclofenac $30 \mu \mathrm{M}$

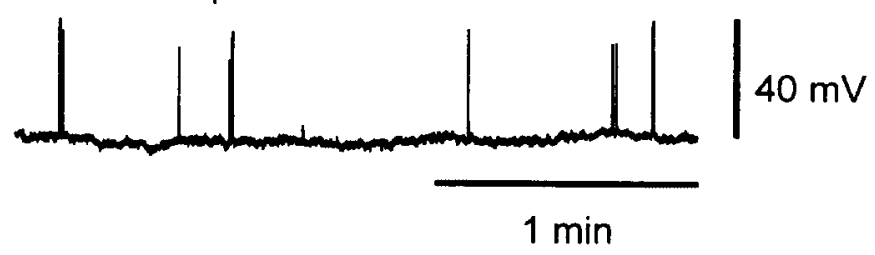

Fig. 3. A typical recording of the electrical activity of a smooth muscle cell from the longitudinal muscle layer of the rat portal vein. Spontaneous bursts of action potentials in the control (upper trace) were inhibited by $30 \mu \mathrm{M}$ diclofenac (bottom trace). Traces were obtained from the same cell both before and $5 \mathrm{~min}$ after the application of diclofenac.

antagonist, changed the amplitude of spontaneous contractions (data not shown). An EP prostanoid receptor antagonist, AH6809, reduced the amplitude of spontaneous contractions in a concentration-dependent manner (Fig. 4). In the presence of $30 \mu \mathrm{M}$ AH6809, the amplitude of spontaneous contractions decreased to $61.8 \pm 7.3 \%(\mathrm{n}=8)$ of that in control, while the $50 \mathrm{mM} \mathrm{K}^{+}$ induced contracture in the presence of $30 \mu \mathrm{M}$ AH6809 was $101.7 \pm 4.1 \%(\mathrm{n}=4)$ of that in control.

\section{Effects of cyclic nucleotide synthesis inhibitors}

The role of cAMP in spontaneous contraction was examined by using SQ22536, an adenylate cyclase inhibitor. The amplitude of spontaneous contractions in the presence of $100 \mu \mathrm{M}$ SQ22536 was $52 \pm 3 \%(n=8)$ of that in control. The inhibitory effect of SQ22536 was 

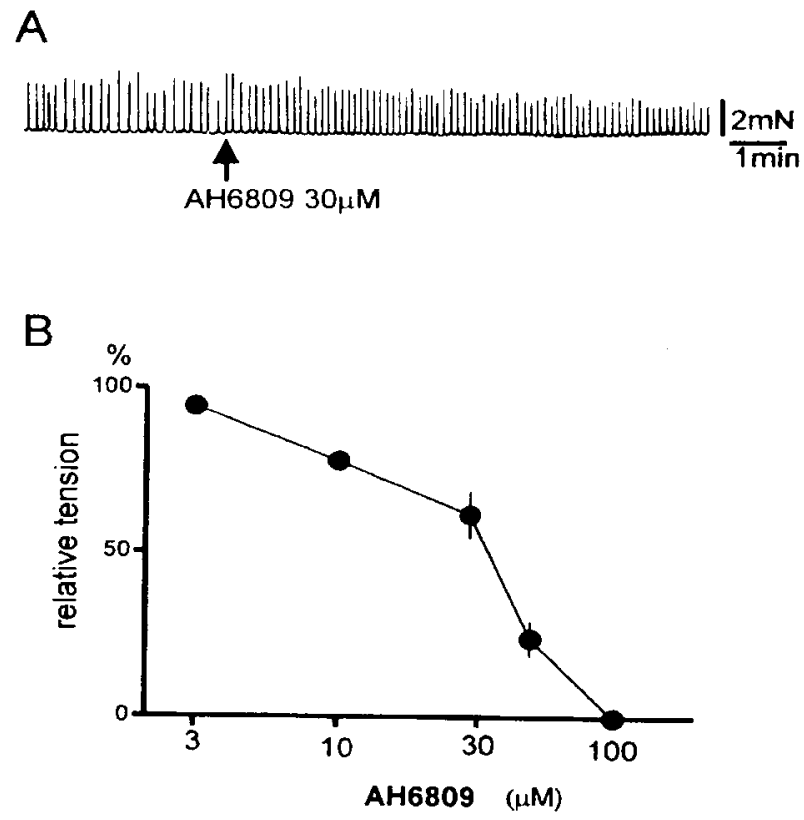

Fig. 4. Effect of the $\mathrm{PGE}_{1}, \mathrm{E}_{2}$ receptor antagonist, $\mathrm{AH6809}$, on spontaneous contractions of longitudinal preparations of the rat portal vein. A: A typical trace shows an inhibitory effect of $30 \mu \mathrm{M}$ AH6809 on spontaneous contraction. B: A summary plot shows the concentration-dependent depression of the amplitude of the spontaneous contractions in the presence of AH6809. Each point represents the mean of 4 to 8 preparations.

concentration-dependent between $30 \mu \mathrm{M}$ and $100 \mu \mathrm{M}$ (Fig. 5). The $50 \mathrm{mM} \mathrm{K} \mathrm{K}^{+}$-induced contracture in the presence of $100 \mu \mathrm{M} \mathrm{SQ} 22536$ was $98.9 \pm 7.0 \%(\mathrm{n}=4)$ of that in control.

The role of cGMP in spontaneous contraction was examined by using ODQ, a guanylate cyclase inhibitor. The amplitude of spontaneous contraction in the presence of $10 \mu \mathrm{M}$ ODQ was $98.1 \pm 1.9 \%(n=5)$ of that in control.

\section{Effects of diclofenac on Lucifer Yellow dye distribution}

After Lucifer Yellow dye was injected into a longitudinal muscle cell from the microelectrode, its intercellular diffusion occurred predominantly in the direction of the longitudinal muscle layer of the preparation. When the area and length of the dye-stained regions were compared between untreated preparations and those treated with $30 \mu \mathrm{M}$ diclofenac, the area and longitudinal distance of dye staining were significantly smaller in the diclofenac-treated preparations when compared to the untreated preparations (Fig. 6).

\section{Discussion}

COX inhibitors have been reported to inhibit the spontaneous tonic contractions of the smooth muscle of the cat esophagus (Cao et al., 1999), the spontaneous rhythmic contractions in the rat renal pelvis (Davidson and Lang, 2000), and the twitch contractions in the rat gastric 


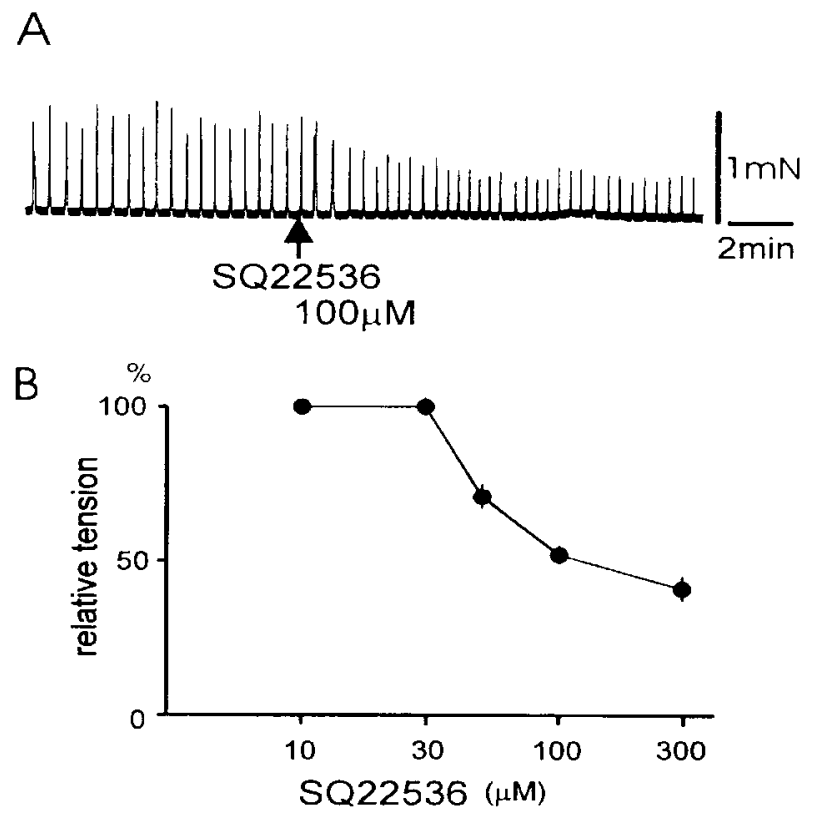

Fig. 5. Effect of the adenylate cyclase inhibitor, SQ22536, on spontaneous contractions of longitudinal preparations of the rat portal vein. A: A typical trace showing the inhibitory effect of $100 \mu \mathrm{M}$ SQ22536 on spontaneous contractions. B: A summary plot showing the concentration-dependent depression of the spontaneous contraction amplitude by SQ22536. Each point represents the mean of 4 to 6 preparations.

A

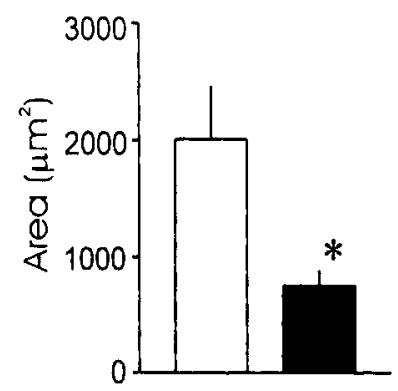

B

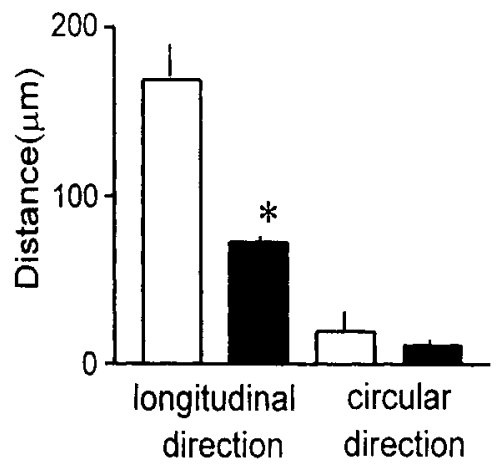

Fig. 6. Changes in Lucifer Yellow dye distribution in longitudinal preparations of the rat portal vein following a 2 min electric current injection from the microelectrode. The area of distribution (A) and the distance of distribution in both the longitudinal and circular directions are compared. Open columns, absence of diclofenac; filled columns, presence of $30 \mu \mathrm{M}$ diclofenac. Data shows the mean of 6 preparations in each experiment. Asterisks indicate statistical significance $(P<0.05)$. 
fundus (Yoneda et al., 2001). It has also been indicated that products of the COX pathway are important in the regulation of vascular smooth muscle contraction (Wright et al., 2001). While meclofenamate, a COX inhibitor, has been reported to inhibit spontaneous contractions of the rat portal vein (Enero, 1979), the detailed mechanism of action is not clear. In the present study, we have observed that diclofenac, another COX inhibitor (Mitchell et al., 1994), decreased the amplitude of spontaneous phasic contractions of longitudinal preparations of the rat portal vein without affecting $50 \mathrm{mM} \mathrm{K}^{+}$-induced contractions. As nicardipine, an L-type $\mathrm{Ca}^{2+}$ channel inhibitor abolished both spontaneous and $50 \mathrm{mM} \mathrm{K} \mathrm{K}^{+}$-induced contractions in this preparation, the inhibition by diclofenac does not involve voltage-dependent $\mathrm{Ca}^{2+}$ channels or nonspecific mechanisms. A relationship between contraction and free intracellular $\mathrm{Ca}^{2+}$ concentration in smooth muscle cells has been reported on the basis of studies using calcium indicators (Morgan and Morgan, 1984). Very little information is available concerning the relationship between contraction and intracellular free $\mathrm{Ca}^{2+}$ concentration in smooth muscle cells of the rat portal vein (Swärd et al., 1993). In the present study, we have observed that each spontaneous phasic contraction was accompanied by a phasic increase in the Fura PE3 $\mathrm{F}_{340} / \mathrm{F}_{380}$ ratio. Since diclofenac decreased both the amplitudes of the spontaneous phasic contractions and the phasic increases in the intensities of the Fura PE3 $\mathrm{F}_{340} / \mathrm{F}_{380}$ ratio in a similar manner, it would appear that the diclofenac-induced inhibition of the spontaneous contractions was mediated by a decrease in the intracellular $\mathrm{Ca}^{2+}$ concentrations. It has been shown that spontaneous contractions of the rat portal vein are accompanied by bursts of action potentials (Funaki and Bohr, 1964; Axelsson et al., 1967; Johansson et al., 1967). Both contraction and action potentials are dependent on an influx of extracellular calcium through L-type Ca ${ }^{2+}$ channels (Sutter, 1990; Kamishima and McCarron, 1996). We observed that diclofenac decreased the number of spikes in each burst of action potentials with an accompanying decrease in the $\mathrm{Ca}^{2+}$ influx. As this agent did not affect the high- $\mathrm{K}^{+}$-induced contraction, it was considered that diclofenac influenced pathways other than voltage-dependent $\mathrm{Ca}^{2+}$ channels. Further investigation would be needed to discriminate between the effects of diclofenac and nicardipine, an L-type channel inhibitor, on action potentials.

Elevation of cAMP increased intercellular communication in both cardiomyocytes, (Burt and Spray, 1988) and osteocytes (Cherian et al., 2003). Thus, formation of cAMP is involved in both electrical cell-to-cell coupling and in spontaneous contractile activity. Generally cell-to-cell conductance has been shown to be increased by elevation of cAMP and decreased by elevation of cGMP (Brink and Barr, 2000). These responses may be mediated via the phosphorylation of connexin, however, its relationship to change in intercellular communication is not clear (Sáez et al., 2003). Several studies have suggested that the inhibition of spontaneous contraction by COX inhibitors is mediated by a decrease in intercellular communication. An earlier study has shown that dye transfer through gap junctions in osteocyte-like MLO-Y4 cells was inhibited by indomethacin and that $\mathrm{PGE}_{2}$ facilitated gap junction-mediated communication in these cells (Cheng et al., 2001). In the canine trachealis muscle, $\mathrm{PGE}_{2}$ or $\mathrm{PGI}_{2}$ increased gap junction formation (Agrawal and Daniel, 1986). It has also been shown that an increase in intercellular communication enhanced the amplitude of spontaneous contractions (Garfield et al., 1988; 1992), while inhibition of intercellular communication reduced myogenic contraction in cerebral 
arteries (Lagaud et al., 2002). However, in cardiac muscle cells, cyclooxygenase metabolites were not involved in gap junction conductance (Schmilinsky-Fluri et al., 1997). In the rat myometrium, generation of gap junctions was inhibited by indomethacin and increased by $\mathrm{PGH}_{2}$ and arachidonic acid (Garfield et al., 1980). The reduction in the distribution of Lucifer Yellow induced by diclofenac observed in the present study is consistent with the findings of the aforementioned studies on smooth muscle. However, in rat myometrium, it was reported that 2deoxy-D-glucose diffusion was reduced by an increase in intracellular cAMP or isoproterenol and $\mathrm{PGE}_{2}$ administration (Cole and Garfield, 1986). This difference in the myometrium might indicate the possible presence of a different regulation by cyclooxygenase pathway from that in the smooth muscle cells of the rat portal vein. In the present study, our results have indicated that the physiological level of cAMP plays an important role in the maintenance of spontaneous contractions. The marked decrease in the distribution of Lucifer Yellow by diclofenac was observed in the longitudinal direction but not in the circular direction. This observation was compatible with the results of the mechanical and electrical recordings from longitudinal preparations.

We observed that ozagrel and SQ29548 did not affect the amplitude of spontaneous contractions; thus, prostanoid TP receptor agonists such as thromboxane and $\mathrm{PGF}_{2 \alpha}$ do not appear to play a role in mediating the contractions. On the contrary, an EP prostanoid receptor antagonist, AH6809 (Janssen et al., 2000; Woodward et al., 1995; Coleman et al., 1985), inhibited the amplitude of spontaneous contractions in the rat portal vein. Since AH6809 did not inhibit contractions induced by $50 \mathrm{mM} \mathrm{K}$, its inhibitory effect on spontaneous contraction appears to involve neither L-type $\mathrm{Ca}^{2+}$ channel-mediated nor nonspecific mechanisms. Thus, it would appear that prostanoid EP receptors are involved in spontaneous contractions of the rat portal vein.

In the present study, SQ22536, an adenylate cyclase inhibitor (Gao and Raj, 2001), decreased the amplitude of the spontaneous contractions of the rat portal vein. Since SQ22536 did not inhibit the $50 \mathrm{mM} \mathrm{K}^{+}$-induced contracture, the inhibition did not appear to involve L-type $\mathrm{Ca}^{2+}$ channel-mediated or nonspecific mechanisms. Since cAMP serves as a second messenger for $\mathrm{PGE}_{2}$, the inhibition of spontaneous contractions by adenylate cyclase inhibition was compatible with the effect of a $\mathrm{PGE}_{2}$ receptor antagonist. As only $50 \%$ of the spontaneous contraction was inhibited by SQ22536, other mechanisms might also be involved in spontaneous contraction. The contribution of cGMP was excluded since ODQ did not affect spontaneous contraction.

In conclusion, these results indicate that diclofenac inhibits the spontaneous contraction of the rat portal vein by decreasing electrical activity. The inhibition of spontaneous contraction may be mediated by the COX pathway. Decreases in the production of cAMP and $\mathrm{PGE}_{2}$, as well as cell-to-cell coupling, would appear to be involved in the inhibition. In the rat portal vein, intrinsic $\mathrm{PGE}_{2}$ plays an important role in the maintenance of spontaneous electrical and mechanical activities.

\section{Acknowledgement}

This study was supported in part by “Academic Frontier" Grants by the Ministry of 
Education, Culture, Sports, Science, and Technology of Japan (2002).

\section{References}

Agrawal, R. and Daniel, E.E. (1986). Control of gap junction in canine trachea by arachidonic acid metabolites. Am. J. Physiol. 250: C495-C505.

Axelsson, J., Phil, D., Wahlström, B., Johansson, B. and Jonsson, O. (1967). Influence of the ionic environment on spontaneous electrical and mechanical activity of the rat portal vein. Circ. Res. 11: 609-615.

Beny, J.-L. (1990). Endothelial and smooth muscle cells hyperpolarized by bradykinin are not dye coupled. Am. J. Physiol. 258: H836-H841.

Beny, J.-L. and Connat, J.-L. (1992). An electron-microscopic study of smooth muscle cell dye coupling in the pig coronary arteries. Roles of gap junctions. Circ. Res. 70: 49-55.

Brink, P. and Barr, L. (2000). The path of intercellular communication: gap junctions. In: A Functional View of Smooth Muscle. eds. by E.E. Bittar, L. Barr, and G.I. Christ, JAI press, Stamford, Connecticut, U.S.A., pp. 397-423.

Burt, J.M. and Spray, D.C. (1988). Inotropic agents modulate gap junction conductance between cardiac myocyte. Am. J. Physiol. 254: H1206-H1210.

Cao, W.B., Harvett, K.M., Chen, Q., Jain, M.K., Behar, J. and Biancani, P. (1999). Group I secreted PLA 2 and arachidonic acid metabolites in the maintenance of cat LES tone. Am. J. Physiol. 277: G585G598.

Cheng, B., Kato, Y., Zhao, S., Luo, J., Sprague, E., Bonewald, L.F. and Jiang, J.X. (2001). PGE 2 is essential for gap junction-mediated intercellular communication between osteocyte-like MLOY4 cells in response to mechanical strain. Endocrinol. 142: 3464-3473.

Cherian, P.P., Cheng, B., Gu, S., Sprague, E., Bonewald, L.F. and Jiang, J.X. (2003). Effects of mechanical strain on the function of gap junctions in osteocytes are mediated through the prostaglandin $\mathrm{EP}_{2}$ receptor. J. Biol. Chem. 278: 43146-43156.

Christ, G.J., Spray, D.C., El-Sabban, M., Moore, L.K. and Brink, P.R. (1996). Gap junctions in vascular tissues. Evaluating the role of intercellular communication in the modulation of vasomotor tone. Circ. Res. 79: 631-646.

Cole, W.C. and Garfield, R.E. (1986). Evidence for physiological regulation of myometrial gap junction permeability. Am. J. Physiol. 251: C411-C420.

Coleman, R.A., Kennedy, I. and Sheldrick, R.L.G. (1985). AH6809, a prostanoid EP ${ }_{1}$ receptor blocking drug. Br. J. Pharmacol. 85: 273.

Davidson, M.E. and Lang, R.J. (2000). Effect of selective inhibitors of cyclo-oxygenase-1 (COX-1) and cyclo-oxygenase-2 (COX-2) on the spontaneous myogenic contractions in the upper urinary tract of the guinea-pig and rat. Br. J. Pharmacol. 129: 661-670.

Enero, M.A. (1979). Effect of drugs on the force of spontaneous mechanical activity in rat portal vein. Acta Physiol. Latinoam. 29: 101-106.

Funaki, S. and Bohr, D.F. (1964). Electrical and mechanical activity of isolated vascular smooth muscle of the rat. Nature 203: 192-194.

Gao, Y. and Raj, J.U. (2001). SQ22536 and W-7 inhibit forskolin-induced cAMP elevation but not relaxation in newborn ovine pulmonary veins. Eur. J. Pharmacol. 418: 111-116.

Garfield, R.E., Blennerhassett, G. and Miller, S.M. (1988). Control of myometrial contractility: role and regulation of gap junctions. Oxf. Rev. Reprod. Biol. 10: 436-490.

Garfield, R.E., Kannan, M.S. and Daniel, E.E. (1980). Gap junction formation in myometrium: control by estrogens, progesterone, and prostaglandins. Am. J. Physiol. 238: C81-C89.

Garfield, R.E., Thilander, G., Blennerhassett, M.G. and Sakai, N. (1992). Are gap junctions necessary for 
cell-to-cell coupling of smooth muscle?: an update. Can. J. Physiol. Pharmacol. 70: 481-490.

Janssen, L.J., Premji, M., Netherton, S., Catalli, A., Cox, G., Keshavjee, S. and Crankshaw, D.J. (2000). Excitatory and inhibitory actions of isoprostanes in human and canine airway smooth muscle. $J$. Pharmacol. Exp. Ther. 295: 506-511.

Johansson, B., Jonsson, O., Axelsson, J. and Wahlström, B. (1967). Electrical and mechanical characteristics of vascular smooth muscle responses to norepinephrine and isoproterenol. Circ. Res. 21: 619-633.

Kamishima, T. and McCarron, J.G. (1996). Depolarization-evoked increases in cytosolic calcium concentration in isolated smooth muscle cells of rat portal vein. J. Physiol. (Lond.) 492: 61-74.

Lagaud, G., Karicheti, V., Knot, H.J., Christ, G.J. and Laher, I. (2002). Inhibitors of gap junctions attenuate myogenic tone in cerebral arteries. Am. J. Physiol. 283: H2177-H2186.

Mitchell, J.A., Akarasereenont, P., Thiemermann, C., Flower, R.J. and Vane, J.R. (1994). Selectivity of nonsteroidal anti-inflammatory drugs as inhibitors of constitutive and inducible cyclooxygenase. Proc. Nat. Acad. Sci. 90: 11693-11697.

Miwa, T., Endou, M. and Okumura, F. (1997). Prostaglandin $E_{1}$ potentiation of the spontaneous phasic contraction of rat isolated portal vein by a cyclopiazonic acid-sensitive mechanism. $\mathrm{Br}$. J. Pharmacol. 120: 1419-1426.

Morgan, J.P. and Morgan, K.G. (1984). Alteration of cytoplasmic ionized calcium levels in smooth muscle by vasodilators in the ferret. J. Physiol. (Lond.) 357: 539-551.

Sáez, J.C., Berthoud, V.M., Brañes, M.C., Martínez, A.D. and Beyer, E.C. (2003). Plasma membrane channels formed by connexins: their regulation and functions. Physiol. Rev. 83: 1359-1400.

Sakai, N., Blennerhassett, M.G. and Garfield, R.E. (1992). Intracelluar cyclic AMP concentration modulates gap junction permeability in parturient rat myometrium. Can. J. Physiol. Pharmacol. 70: 358-364.

Schmilinsky-Fluri, G., Valiunas, V., Willi, M. and Weingart, R. (1997). Modulation of cardiac gap junctions: the mode of action of arachidonic acid. J. Mol. Cell Cardiol. 29: 1703-1713.

Shimamura, K., Zhou, M., Toba, M., Kimura, S., Higuchi, T., Kawaguchi, H., Sekiguchi, F. and Sunano, S. (2003). Effects of L-arginine on spontaneous contraction of the rat portal vein. Pflügers Arch. 446: 30-35.

Sutter, M.C. (1990). The mesenteric-portal vein in research. Pharmacol. Rev. 42: 287-325.

Swärd, K., Josefsson, M., Lydrup, M.-L. and Hellstrand, P. (1993). Effects of metabolic inhibition on cytoplasmic calcium and contraction in smooth muscle of rat portal vein. Acta. Physiol. Scand. 148: $265-272$.

Vidulescu, C., Mironneau, J., Mironneau, C. and Popescu, L.M. (2000). Messenger molecules of the phospholipase signaling system have dual effects on vascular smooth muscle contraction. J. Cell Mol. Med. 4: 196-206.

Woodward, D.F., Pepperl, D.J., Burkey, T.H. and Regen, J.W. (1995). 6-Isopropoxy-9-oxoxanthene-2carboxylic acid (AH 6809), a human EP2 receptor antagonist. Biochem. Pharmacol. 50: 17311733.

Wright, D.H., Abran, D., Bhattacharya, M., Hou, X., Bernier, S.G., Bouayad, A., Fouron, J.-C., VazquezTello, A., Beauchamp, M.H., Clyman, R.I., Peri, K., Varma, D.R. and Chemtob, S. (2001). Prostanoid receptors: ontogeny and implications in vascular physiology. Am. J.Physiol. 281: R1343-R1360.

Yoneda, S., Kito, Y. and Suzuki, H. (2001). Inhibitory actions of indomethacin on electrical and mechanical responses produced by nerve stimulation in circular smooth muscle of the guineapig gastric fundus. J. Smooth Muscle Res. 37: 81-93.

(Received April 19, 2005; Accepted June 30, 2005) 